\title{
Yhdyssanat ja yhdyssanamaiset rakenteet Mikael Agricolan teoksissa
}

\author{
TANJA TOROPAINEN
}

\section{Väitöksenalkajaisesitelmä Turun yliopistossa 25. elokuuta 2017}

Yhdyssanoissa on voimaa. Harva muu kielenpiirre herättää kielenkäyttäjissä toistuvasti yhtä vahvoja tunteita kuin yhdyssanat tai varsinkin yhdyssanavirheet, joista ihmiset näpäyttelevät toisiaan sosiaalisessa mediassa.

Yhdyssanoissa on muunkinlaista voimaa. Niiden välityksellä kieleen on saatu lukemattomia uusien käsitteiden nimityksiä. Nykykielen uusista sanoista suurin osa on yhdyssanoja (esim. Häkkinen 1990: 144), ja yhdyssanojen muodostus on kirjakielessä aina ollut tärkeä sananmuodostuskeino.

Kun tavallisillakin kielenkäyttäjillä tuntuu olevan vankkaa ja varmaa tietoa yhdyssanoista, voisi luulla, että kielenkuvauksessa yhdyssanat olisivat ongelmaton ja helposti kuvattava sanaryhmä. Todellisuus on kuitenkin toinen. Yhdyssanan käsitteen tyhjentävä määrittely ei ole täysin onnistunut nykykielen osalta, vaikka nykykieltä sinänsä on tutkittu paljon (esim. Tyysteri 2015: 23-44; Toropainen 2017: 27-32). Vanhan kirjakielen tutkimuksessa yhdyssanat ovat osoittautuneet vieläkin hankalammaksi kategoriaksi, ja varmaan siksi vanhan kirjakielen yhdyssanojen tutkimus on ollut melko vähäistä.

Onkin oikeastaan aiheellista kysyä, onko vanhan kirjakielen yhdyssanojen ja yhdyssanarakenteiden tutkiminen mielekästä ja kannattaako tutkia ilmiötä, joka kategoriana on kovin häilyvä. Vastaan näihin kysymyksiin lektion lopussa. Ensin havainnollistan parilla esimerkillä sitä, miten yhdyssanan kategorian häilyvyys ilmenee Agricolan teoksissa.

(1) Sen pite sinun palcas ia osas oleman / ionga mine sinullen mitanut olen / sanopi Herra / Sentehden ettes minun wnochtanut olet / ia wskalsit walhen pälle (A-I-140-[Jer-13:25])

1. Esimerkit ovat Kotimaisten kielten keskuksen Kaino-aineistopalvelusta, joka on käytettävissä osoitteessa kaino.kotus.fi. Lähdeviitteet noudattavat Kaino-korpuksen käytäntöä. 
Ensimmäisessä esimerkissä tarkasteltava yhdyssana tai yhdyssanamainen rakenne on sentähden, joka esiintyy lauseessa adverbiaalina ja on tulkintani mukaan yhdysperäinen adverbi. Yhdyssanaksi tulkitsemista puoltaa se, että peräkkäiset sanat se ja tähden on kirjoitettu yhteen. Tulkintaa vastaan puhuu nykykieli ja siinä oleva sääntö, jonka mukaan pronomini ja postpositio kirjoitetaan toisistaan erilleen (esim. Kielitoimiston oikeinkirjoitusopas 2007: 254). Voiko Agricolalla esiintyvä sanajono olla yhdyssana, jos nykykielessä pidämme vastaavaa sanajonoa sanaliittona? Mielestäni voi, koska kirjakieltä koskevat säännöt on luotu vasta Agricolan ajan jälkeen ja koska säännöt ovat luonteeltaan sopimuksia (ks. esim. Kolehmainen 2014).

(2) HERRA / quinga cauuan sine täte catzelet? pelasta sijs minun Sielun heiden Mässestens / Ja minun yxinäijsen Jaloijstpeuroijsta (A-I-279-[Ps-35:17])

Toisessa esimerkissä jalopeura-sana käyttäytyy erikoisesti: sen molemmat osat ovat taipuneet sijamuodossa. Tapaus on Agricolankin teoksissa ainutlaatuinen jalopeurasanan yhteydessä, sillä aina muulloin sanan alkuosa on taipumaton ja vain jälkiosa on taipunut (jalopeuroista) (Toropainen 2015: 67). Onko tässä esiintymässä kyse yhdyssanasta vai sanaliitosta? Merkityksen perusteella on ilman muuta kyse yhdyssanasta. Tulkintaa tukee myös tieto, että jalopeura-lekseemi on Agricolan teoksissa hyvin yleinen, esiintymiä on yli 7o. Tulkintaa vahvistaa lisäksi tieto eräästä Agricolan teosten tyypillisyydestä: adjektiivista ja substantiivista muodostuneissa yhdyssanoissa (kuten omatunto) molemmat osat taipuvat, kun niitä käytetään lauseessa. Esimerkiksi ilmauksessa poden huonoa omaatuntoa molemmissa osissa on partitiivimuoto. (Mas. 65, 67.) Kummankin osan taipuminen on tyypillistä tietynlaisille sanaliitoille ja lausekkeille mutta epätyypillistä yhdyssanoille. Kategoria siis häilyy, mutta merkitys osoittaa tässä tapauksessa peräkkäisten sanojen leksikaalisen yhteenkuuluvuuden.

(3) Sencaltainen Tieto ombi minulle ylenihmelinen ia ylencorkia (A-III-42O[Ps-139:6])

Kolmannessa esimerkissä adverbi ylen on kirjoitettu yhteen sitä seuraavien adjektiivien ihmeellinen ja korkia kanssa. Nykykielen perusteella yhteen kirjoittaminen pitäisi tulkita virheeksi, koska ylen-sanan voi vain määrätapauksissa, kuten verbissä ylenantaa, kirjoittaa yhteen sitä seuraavan sanan kanssa. Pitäisikö nämä tapaukset siis yksinkertaisesti vain tulkita kirjoitusvirheiksi? Ratkaisu olisi turhan yksioikoinen ja jättäisi huomiotta sen, että $y l e n$-sana esiintyy Agricolan teoksissa lähes 600 kertaa ja vain 27 tapauksessa se on kirjoitettu erikseen sitä seuraavasta sanasta (Toropainen 2014: 32). Yhteen kirjoittaminen on siis tarkoituksellisesta, mutta osoittaako kirjoitusasu sen, että kyseessä on yhdyssana? En ole varma asiasta. Kokonaisuudella ei tunnu olevan eriytynyttä merkitystä. Yhteen kirjoittamiselle on kuitenkin selitys: Agricola on hahmottanut ylen-aineksen prefiksiksi, etuliitteeksi, ja vanhassa kirjasuomessa on aivan tavallista kirjoittaa etuliitteet yhteen niitä seuraavan sanan kanssa (Vaittinen 2003, 2007). Tässä tapauksessa sanajonon yhdyssanatulkinta jää avoimeksi ja on turvallisempaa puhua yhdyssanamaisesta rakenteesta. 
(4) ia henen Corkian Schouluns Opetuslapsist / ioca sanotan nijsse Makunnis wiele nyt seisoua (A-III-593-[Dan-e:o])

Neljännessä esimerkissä mielenkiintoinen on sanajono korkian skouluns, siis korkean koulunsa. Kyse ei ole korkeasta koulurakennuksesta vaan jonkinlaisesta korkean opetuksen opinahjosta. Nykysuomessa tällainen ilmaus tulkittaisiin yhdyssanaksi ja kirjoitettaisiin yhteen. Lisäksi alkuosa olisi taipumaton: korkeakoulunsa. Onko tämä sanajono Agricolan teoksissa yhdyssana? Mielestäni ei ole. Merkityksen puolesta kokonaisuuden voi hahmottaa yhdyssanaksi, mutta taipuvan alkuosan, sanarakenteen ja erikseen kirjoittamisen perusteella nimitän tapausta liittosanaksi, jota pidän yhtenä yhdyssanamaisena rakennetyyppinä (ks. termistä liittosana Toropainen 2017: 35-36).

Edellä esitellyt ja analysoidut esimerkit havainnollistavat yhdyssanakategorian rajaamisen ja määrittelemisen vaikeutta. Toisaalta esimerkit kuvastavat myös sitä, että Agricolan teoksissa on perussanojen, johdosten ja yhdyssanojen lisäksi liittomuotoinen sanarakennetyyppi. Näiden liittosanojen ja yhdyssanojen välinen raja on kuitenkin epämääräinen ja vaatii vielä lisätutkimusta.

Onneksi Agricolan teoksissa on aivan selviäkin yhdyssanoja, joten kategorian olemassaoloa sinällään ei tarvitse epäillä tai kyseenalaistaa. Esimerkiksi erilaisia yhdyssubstantiiveja on yli 1200 (Toropainen 2017: 53). Mainittakoon niistä vaikkapa muutama k:lla alkava sana: kalamies, kamelinvarsa, kanssaperillinen, kaulahopea, keisarikunta, kesäkuu, kiirastuli, kivimuuri, koiruoho, korkoraha, kullanseppä, kulmakunta, kylkiluu ja käskysana.

Agricolan teosten tyylille ovat ominaisia prefiksialkuiset yhdyssanat, varsinkin verbit, kuten poisottaa, uloskäydä, ylenantaa, ylesnousta. Etuliitteisissä yhdyssanoissa näkyy vieraiden kielten vaikutus. Muutenkin Agricolan yhdyssanojen joukossa on paljon osa osalta muodostettuja käännöslainoja. (Vaittinen 2003; Toropainen 2017: erityisesti luvut 5 ja 6 sekä liitteet.)

Agricolan teosten yhdyssanat jakautuvat sanaluokkiin eri tavalla kuin nykykielessä. Nykyisin teksteissä esiintyvistä yhdyssanoista 82 prosenttia on yhdyssubstantiiveja, kun Agricolalla vastaava osuus on vain 35 prosenttia. Agricolan teksteissä korostuvatkin yhdysperäiset verbit ja adverbit. (Toropainen 2017: 55.)

Agricolan teosten ortografiaa ja varsinkin sanayhtymien yhteen ja erikseen kirjoittamista on pidetty hyvin epäsäännöllisenä ja epäjohdonmukaisena. Näin olen ajatellut itsekin. Tutkimukseni edetessä käsitykseni on kuitenkin muuttunut. Sanayhtymien yhteen kirjoittaminen on erilaista kuin nykykielessä, ja havaittavissa on epäsäännöllisyyttäkin - onhan kyse ensimmäisistä uudella kirjakielellä kirjoitetuista kirjoista. Sanayhtymien kirjoittamisessa on kuitenkin nähtävissä käytäntö, jossa merkityksensä puolesta yhteen kuuluvat, tekstissä peräkkäin esiintyvät sanat on kirjoitettu yhteen. Yhteen kirjoitetuista yhtymistä muodostuu usein ilmeisiä käsitteiden nimityksiä. (Toropainen 2014: 57; 2015: 82; 2016: 195; 2017: 48-52.)

Ortografian kannalta kenties kiinnostavin yhdyssanojen joukko ovat niin sanotut luontaiset yhdyssanat. Ne ovat sanarakenteita, joilla ei ole kielessä vastaavaa kaksisanaista syntaktista rakennetta. Sanat ovat rakenteensa puolesta välttämättä yhdyssanoja. Näiden yhdyssanojen alkuosana on nominatiivimuoto, yhdysosamuoto tai lek- 
seeminä esiintymätön nominivartalo. Jälkiosana on substantiivi tai adjektiivi, ja tavallisimmin luontaiset yhdyssanat ovat nimenomaan substantiiveja. (ISK 2004: \$400; Koivisto 2013: 329-330; Toropainen 2016: 176; 2017: 29.) Esimerkiksi nominatiivimuodolla alkava sana väitöskirja on luontainen yhdyssana. Nämä ovat juuri niitä yhdyssanoja, joiden osien erikseen kirjoittaminen kuohuttaa somekansaa.

Viimeisimmässä osatutkimuksessani (Toropainen 2016) selvitin, miten luontaiset yhdyssanat on kirjoitettu Agricolan teoksissa. Yleensä, reilusti yli 5 ooo tapauksessa, luontaisten yhdyssanojen osat on kirjoitettu yhteen. Erikseen kirjoitettuja tapauksia oli alle 6 prosenttia kaikista tapauksista. Tutkimus paljasti myös toisen kiinnostavan asian: kirjojen painoasu, typografia, on vaikuttanut sanayhtymien yhteen ja erikseen kirjoittamiseen. (Erityisesti mas. 194.)

Typografia johdattaa pohtimaan tutkimuksessa käytettyjen aineistojen olemusta ja luotettavuutta. Agricola-tutkimuksessa tekstimuotoiset digitoidut aineistot ovat tärkeitä. Ne tarjoavat muun muassa mahdollisuuden kerätä tutkimusaineistoa suhteellisen nopeasti ja helposti. Yksi digitoiduista aineistoista on Kaino-korpus. Korpus voi johtaa kuitenkin yhdyssanatutkijan harhaan, sillä korpuksen perusteella syntyy vaikutelma, että edellä kuvattujen luontaisten yhdyssanojen ortografian vaihtelu on Agricolan teoksissa mainittua yleisempää. Tämä johtuu siitä, että korpusta koottaessa ei ole kaikissa kohdin otettu huomioon 150o-luvun typografisia käytäntöjä eli esimerkiksi sitä, että kun sana jakautuu rivinvaihtokohdassa kahdelle riville, läheskään aina ei ole käytetty tavuviivaa (Toropainen 2016: 184-187).

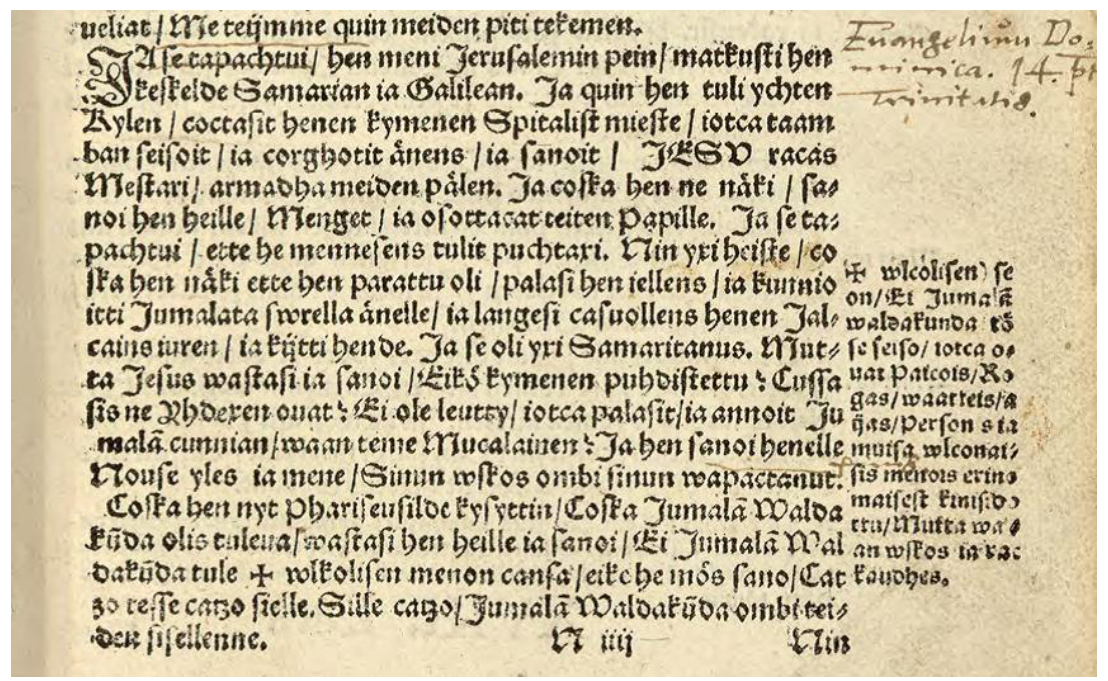

Kuva 1.

Katkelma Luukkaan evankeliumista Agricolan Uudesta testamentista (1548). Kuva: Kansalliskirjasto.

Kuvassa 1 on katkelma Uudesta testamentista Luukkaan evankeliumin 17. luvusta. Kuvassa näkyy useita esimerkkejä rivinvaihtokohdassa olevista sanoista. Joissakin kohdissa on käytetty tavuviivaa (sa-noi, ta-pachtui, Jal-cains, Mut-ta, tei-den), mutta mo- 
nissa kohdissa tavuviiva on jätetty pois joko tavu- tai äännerajalta (taam $|b a n, c o| s k a$, kunnio|itti, Ju|malan, Wal|dakunda, Cat $\mid z o$ ) tai tavuviiva on jätetty pois yhdysosien rajalta (Walda|kunda).

Sellaisissa tavuviivattomissa tapauksissa, joissa riveille jakaminen osuu sanan tavutai äännerajalle, eri riveillä olevat sanan osat on Kaino-korpuksessa ilman muuta tulkittu samaan sanaan kuuluviksi. Sen sijaan tapaukset, joissa tavuviiva puuttuu yhdysosien rajalta, on tulkittu kuvan 1 esittämässä tapauksessa ja usein muissakin tekstinkohdissa erillisiksi sanoiksi. (Toropainen 2016: 184-186.) Vain kohdan lukeminen alkuperäisteoksesta tai näköispainoksesta paljastaa, että tapauksen voikin tulkita yhdyssanaksi.

Aiemmin esitellessäni kategorioiden rajalla häilyviä sanayhtymiä mainitsin toistuvasti, millä tavalla tapaus tulkittaisiin nykykielessä. Nykykieli tunkeutuu helposti tulkintoihin, joita vanhasta kielestä tehdään, ja nykykieli ja sitä koskeva tieto näyttävät vaikuttaneen vanhasta kirjakielestä koottuihin aineistoihin. Esimerkiksi sanalippukokoelmissa voivat olla yliedustettuina sellaiset sanarakenteet, jotka elävät yhä nykykielessä. Erikoisimmat, kielenkäytöstä kadonneet rakenteet on puolestaan voitu kokonaan jättää poimimatta aineistoon (Toropainen 2015: 60, 81). Tätä voi kai luonnehtia voittajien tai voittaneiden muotojen kielenhistoriaksi.

Yhdysverbitutkimusta tehdessäni huomasin, että epäsuomalaisena ja huonona pidetyn rakennetyypin sanastamiseen on liittynyt problematiikkaa, joka heijastuu aineiston luotettavuuteen ja kattavuuteen. Käyttämässäni Vanhan kirjasuomen sanakirjan aineskokoelmassa on yhdysverbeihin liittyviä aukkoja, jotka johtuvat muun muassa siitä, että kirjallisia käännöslainoja on poimittu sanalippuihin liian vähän. Myös lekseemien kirjoittaminen sanalippuihin ja sanalippujen aakkostaminen osoittavat, että yhdysverbit ovat aiheuttaneet vaikeuksia sanastajille. Toisinaan yhtymän määriteosa on kirjoitettu sulkeisiin edusosan edelle, toisinaan määriteosa on edusosan jäljessä erikseen kirjoitettuna. Kuitenkin sanalipun esimerkki näissä tapauksissa osoittaa, että kyseessä on yhdysverbi tai sellainen sanaliitto, jossa määrite on edussanansa edellä. Joskus yksiselitteiset yhdysverbit on aakkostettu edusosansa mukaan. Toisin sanoen yhdysverbejä on käsitelty kuten nykykielessä, jossa määriteosa seuraa edussanaa tai yhdysverbi on korvattu yksinäisverbillä. Tästä syntyy vaikutelma, että prefiksialkuisuus ja vierasperäisyys on yritetty häivyttää aineistosta. (Vaittinen 2003: 46; Toropainen 2017: 40.)

Agricolan ja laajemmin vanhan kirjakielen yhdyssanojen tutkijan pitääkin olla valppaana ja käyttää monenlaisia aineistoja. Myös tulkinnassa on syytä tietoisesti irrottautua nykykielen yhdyssanakäsityksestä. (Toropainen 2017: 45-46, 77-78.) Nykykieltä voi käyttää peilinä, mutta vanhaa kirjakieltä pitää kuvata oman aikakautensa ehdoin ja sellaisena kuin kielimuoto todella on ollut olemassa.

Palaan vielä lyhyesti alussa esittämiini kysymyksiin: onko vanhan kirjakielen yhdyssanojen ja yhdyssanarakenteiden tutkiminen mielekästä ja kannattaako tutkia ilmiötä, joka kategoriana on kovin häilyvä?

Vastaan kysymyksiin: tietysti. On selvää, että yhdyssanoja on mielekästä tutkia ja että kannattaa perehtyä häilyväiseen ilmiöön. Vanhan kirjakielen tekstit tarjoavat hyvän aineiston yhdyssanojen ja yhdyssanamaisten rakenteiden rajankäynnin pohtimiseen. Aihe on kielihistoriallisestikin tärkeä. Yhdyssanojen rakennetyyppien kautta on mahdollista tarkastella keinoja, joilla uuteen kirjakieleen luodaan ja tuodaan ilmaisuvaroja. Varhai- 
nen kirjakieli on kielimuotona omanlaisensa. Sitä eivät säännöt kahlitse samalla tavalla kuin nykykirjakieltä, mikä näkyy sanastossa paikoitellen varsin luovina ratkaisuina - tai kuten Agricola (1548) sanoisi: "eksyttynä, outona, kamalana eli uudestipantuna"2.

\section{Lähteet}

Agricola, Mikael 1987 [1548]: Se Wsi Testamenti. Uudistettu näköispainos. Helsinki: WSOY.

HÄ Kkinen, KAISA 1990: Mistä sanat tulevat. Suomalaista etymologiaa. Tietolipas 117. Helsinki: Suomalaisen Kirjallisuuden Seura.

ISK= Hakulinen, Auli - Vilikuna, Maria - Korhonen, Riitta - Koivisto, Vesa

- Heinonen, Tarja Rittta - Alho, Irja 2004: Iso suomen kielioppi Helsinki: Suomalaisen Kirjallisuuden Seura.

Kielitoimiston oikeinkirjoitusopas. Toinen, korjattu painos. Helsinki: Kotimaisten kielten tutkimuskeskus 2007.

Koivisto, Vesa 2013: Suomen sanojen rakenne. Suomi 202. Helsinki: Suomalaisen Kirjallisuuden Seura.

Kolemmainen, TARU 2014: Kielenhuollon juurilla. Suomen kielen ohjailun historiaa. Suomi 204 ja Kotimaisten kielten keskuksen julkaisuja 174. Helsinki: Suomalaisen Kirjallisuuden Seura.

Toropainen, TAnja 2014: Ylen-alkuiset sanat Mikael Agricolan teoksissa. - Sananjalka 56 S. $29-49$.

_ 2015: Adjektiivialkuiset yhdyssubstantiivit Mikael Agricolan teoksissa. - Sananjalka 57 s. 54-85.

2016: Typografian vaikutus yhdyssubstantiivien oikeinkirjoitukseen Agricolan teoksissa. - Sananjalka 58 s. 175-198.

2017: Yhdyssanat ja yhdyssanamaiset rakenteet Mikael Agricolan teoksissa. Annales Universitatis Turkuensis C 439. Turku: Turun yliopisto.

Tyysteri, LAURA 2015: Aamiaiskahvilasta ötökkätarjontaan. Suomen kirjoitetun yleiskielen morfosyntaktisten yhdyssanarakenteiden produktiivisuus. Annales Universitatis Turkuensis C 408. Turku: Turun yliopisto.

VAittinen, TANJA 2003: Vanhan kirjasuomen yhdysverbit. - Sananjalka 45 s. 45-66.

_ 2007: Mikael Agricolan teosten yhdysadjektiivit. - Virittäjä 111 s. 523-542.

Tanja Toropainen: Yhdyssanat ja yhdyssanamaiset rakenteet Mikael Agricolan teoksissa. Annales Universitatis Turkuensis C 439. Turku: Turun yliopisto 2017. Artikkeliväitöskirjan yhteenveto-osa on luettavissa osoitteessa http://www.doria.fi/handle/10024/143331.

Kirjoittajan yhteystiedot: etunimi.sukunimi@utu.fi

2. Lainaus on Agricolan Uuden testamentin toisen esipuheen lopusta: Elken sis iocu Christittu ia Jumalinen Inhiminen / taica temen P. kirian Lukia / site pahaxi ottaco / ios tesse esken alghetussa Somenkielen Tulkituxes / iotakin osa olla exytty / outo ia camala / eli wdhesti pandu (A-II-019-[UT-e]). 